\title{
Similar Survival in Patients Following Heart Transplantation Receiving Induction Therapy Using Daclizumab vs. Basiliximab
}

\author{
Spencer T. Martin; Tomoko S. Kato, MD, PhD; Maryjane Farr, MD; \\ Jaclyn T. McKeen; Faisal Cheema, MD; Mengxi Ji, BSc; Alexandra Ross; \\ Halit Yerebakan, MD; Yoshifumi Naka, MD, PhD; Hiroo Takayama, MD, PhD; \\ Susan Restaino, MD; Donna Mancini, MD; P. Christian Schulze, MD, PhD
}

Background: Induction therapy with interleukin-2 receptor antagonists has been established as an effective immunosuppressive strategy in the management of heart transplant (HTx) recipients. We compared outcomes following HTx in patients receiving basiliximab, daclizumab, or no induction therapy.

Methods and Results: We investigated post-transplant prognosis of patients receiving basiliximab ( $\mathrm{n}=67$ ), daclizumab $(n=98)$ or no induction therapy $(n=70)$. Patients treated with daclizumab $(50.3 \pm 14.7$ years) were younger than those receiving basiliximab $(55.8 \pm 11.2$ years) or no induction therapy $(54.9 \pm 14.1$ years; both $\mathrm{P}<0.05)$. Patients receiving either induction therapy showed better survival 1 year after HTx (95\%) than those without induction therapy (82\%; $P<0.001)$. Survival was similar between patients receiving basiliximab and daclizumab. The incidence of acute cellular or antibody-mediated rejections did not differ among the groups. The main reason that patients did not receive induction therapy was ongoing infection (65.7\%), which was more common in patients on ventricular assist device (VAD) support than those without VAD (76.1\% vs. 45.8\%; $\mathrm{P}=0.004)$. The VAD-related infection rate in the entire study cohort was $29.7 \%$ (35/118 VAD recipients).

Conclusions: Survival following HTx was worse in patients not receiving induction therapy. No differences were noted in survival or the incidence of rejection between the daclizumab- and basiliximab-treated groups. Induction therapy was less used in patients with infection, which was related to prior VAD support. (Circ J 2015; 79: 368-374)

Key Words: Heart transplantation; Immunosuppressant; Induction therapy; Prognosis

$\mathbf{T}$ he availability of immunosuppressive medications for use in heart transplantation (HTx) has remained virtually unchanged over the past decade. Despite this, the need for hospitalization within 1 year after HTx due to rejection decreased from $41 \%$ in 2000 to $26 \%$ in $2009,{ }^{1}$ in large part due to advances in immunosuppressive strategies. ${ }^{2}$ Induction therapy, a selective and highly potent immunosuppressive therapy typically used perioperatively, is 1 strategy that aims to reduce the incidence and severity of acute cellular rejection (ACR). ${ }^{3}$ Induction therapy may maximize outcomes in high-risk patients for rejection, decrease exposure to and/or the dose of nephrotoxic agents, such as calcineurin inhibitors, immediately postoperatively, and facilitate minimization or withdrawal of maintenance immunosuppression. ${ }^{4-6}$ Disadvantages to using these potent therapies include an increased risk of infectious complications, malignancy, and infusion-related or anaphylactic reactions. ${ }^{7}$ Indeed, the use of induction therapy as an immunosuppressive strategy in HTx has continued to increase over the past decade. At present, more than $50 \%$ of all adult heart transplant recipients receive induction therapy. ${ }^{1}$

Daclizumab and basiliximab are chimeric murine/human, monoclonal antibodies that have been approved for use or are

Received June 30, 2014; revised manuscript received October 24, 2014; accepted November 10, 2014; released online December 12, 2014 Time for primary review: 28 days

Department of Pharmacy, Hartford Hospital, Hartford, CT (S.T.M.), USA; Heart Center, Juntendo University School of Medicine, Tokyo (T.S.K.), Japan; Department of Medicine, Division of Cardiology (T.S.K., M.F., M.J., A.R., S.R., D.M., P.C.S.), Department of Surgery, Division of Cardiothoracic Surgery (F.C., H.Y., Y.N., H.T.), Columbia University Medical Center, New York, NY; and Department of Pharmacy, Hackensack Medical Center, Hackensack, NJ (J.T.M.), USA

The first two authors contributed equally to this work (S.T.M., T.S.K.).

Mailing address: Tomoko S. Kato, MD, PhD, Heart Center, Juntendo University School of Medicine, Building 9, 1F-Room124A, 2-1-1

Hongo, Bunkyo-ku, Tokyo 113-8431, Japan. E-mail: rinnko@sannet.ne.jp, tokato@juntendo.ac.jp

ISSN-1346-9843 doi:10.1253/circj.CJ-14-0718

All rights are reserved to the Japanese Circulation Society. For permissions, please e-mail: cj@j-circ.or.jp 
being used in clinical trials in the USA, Europe or Asian countries, including Japan, for the prevention of ACR in renal transplant recipients. By binding the $\mathrm{CD} 25$ protein on naïve $\mathrm{T}$ cells, they effectively antagonize interleukin (IL)-2 signaling and inhibit T-cell activation and proliferation. ${ }^{8}$ Additional induction agents used in HTx include polyclonal anti-thymocyte globulins (equine or rabbit) and alemtuzumab. ${ }^{5}$ Previously, Columbia University Medical Center undertook a randomized prospective trial that determined daclizumab was effective in reducing the frequency of acute rejection episodes in cardiac transplant recipients compared with a control arm. ${ }^{9}$ Furthermore, a multicenter double-blind randomized trial in adult heart transplant recipients demonstrated that daclizumab decreased the incidence of ACR (conventional International Society for Heart and Lung Transplant [ISHLT] grade 3A or higher, grade $2 \mathrm{R}$ or higher), hemodynamic compromise, the need for inotropic support and pulse-dosed corticosteroids, death and retransplantation compared with placebo. ${ }^{10}$

In 2009, the manufacturer of daclizumab ceased production of the agent, and the supplies for clinical use were subsequently exhausted by early $2010 .^{7}$ Consequently, heart transplant programs using daclizumab induction therapy have changed their strategy to use basiliximab induction, which is the only IL-2 antagonist currently available. To date, there have been no direct comparisons of daclizumab and basiliximab in HTx. The purpose of the present study was to compare HTx outcomes of patients receiving daclizumab, basiliximab, or no induction therapy.

\section{Methods}

\section{Study Design}

The present study was a single-center retrospective cohort study of consecutive adult patients who underwent HTx between January 2008 and October 2011 at Columbia University Medical Center. Patients were included in the study if they were 18 years of age or older. Inpatient and outpatient medical records were reviewed for demographic data, clinical characteristics, laboratory results, immunosuppressive therapies, and posttransplant outcomes. Patients were followed for at least 1 year after transplantation or until death. This study was approved by the Columbia University Medical Center Institutional Review Board.

\section{Immunosuppressive Protocol}

Patients deemed appropriate candidates for induction immunosuppression were given daclizumab or basiliximab. In March 2010, our program switched from daclizumab-based induction therapy to basiliximab-based induction therapy. Daclizumab therapy consisted of $1 \mathrm{mg} / \mathrm{kg}$ given intravenously (i.v.) within $24 \mathrm{~h}$ of transplantation, with repeated doses every 2 weeks for a total of 5 doses. Basiliximab was given as a $20-\mathrm{mg}$ i.v. dose within $24 \mathrm{~h}$ of transplantation and on postoperative day (POD) 4. Induction therapy was deferred in patients being retransplanted or in those with an active or recent infection, such as ventricular assist device (VAD)-related infection, at the time of transplantation.

All patients received maintenance immunosuppressive therapy consisting of tacrolimus or cyclosporin, mycophenolate mofetil (MMF), and corticosteroids. Calcineurin inhibitor therapy was initiated postoperatively at the discretion of the heart transplant team. Tacrolimus dose adjustments were based on goal whole-blood trough concentrations of $10-15 \mathrm{ng} / \mathrm{ml}$ for the first 90 days after transplantation and $5-10 \mathrm{ng} / \mathrm{ml}$ thereafter. Cyclosporin dose adjustments were based on goal whole- blood trough concentrations of $250-350 \mathrm{ng} / \mathrm{ml}$ for the first 90 days after transplant, 200-300 ng/ml from POD 91 to 180, and $100-200 \mathrm{ng} / \mathrm{ml}$ thereafter. The choice of cyclosporin or tacrolimus as calcineurin inhibitor therapy was based on a patient's individual comorbidities and physician preference. Initial dosing of MMF was $1,500 \mathrm{mg}$ twice daily. Dosage adjustments of MMF were made in the event of severe myelosuppression or gastrointestinal intolerance. Corticosteroid therapy was initiated in the operating room with $1,000 \mathrm{mg}$ i.v. methylprednisolone, followed by $125 \mathrm{mg}$ i.v. every $8 \mathrm{~h}$ for 3 doses. On POD 1 , a corticosteroid taper began at $50 \mathrm{mg}$ prednisone twice daily (or the methylprednisolone equivalent) and decreased by $10 \mathrm{mg} /$ day to a dose of $15 \mathrm{mg}$ twice daily. Prednisone was further reduced by $5 \mathrm{mg}$ /day following each negative endomyocardial biopsy until a final dose of 5 or $2.5 \mathrm{mg}$ once daily was reached, or until a patient could be steroid free, depending on an individual postoperative course. The use of mammalian target of rapamycin (mTOR) inhibitors was limited to selected patients, such as those at risk for transplant coronary artery disease or malignancy, and mTOR inhibitors were not used during the early postoperative period because they are associated with an increased incidence of surgical complications and delayed wound healing.

All patients received 6-12 months of single-strength trimethoprim-sulfamethoxazole once daily for Pneumocystis jirovecii pneumonia prophylaxis after transplantation. Atovaquone $1,500 \mathrm{mg}$ once daily was used in patients with sulfa allergy, persistent leukopenia, hyperkalemia, or renal dysfunction. Valganciclovir was also used for 6-12 months in all patients at risk of cytomegalovirus (CMV) disease (donor or recipient CMV seropositive). In cases where both the donor and recipient were CMV seronegative, acyclovir was given as prophylaxis against herpes simplex virus. All patients received nystatin for thrush prophylaxis for at least 6 months. 3-Hydroxy-3-methylglutaryl coenzyme A (HMG-CoA) reductase inhibitors, such as pravastatin or atorvastatin, were prescribed to all patients, except for those with documented contraindications to therapy.

Patients presenting with a low-grade, asymptomatic ACR episode (grade 1R/1B) were treated with an oral steroid pulse (100 mg prednisone) with a rapid taper to their baseline prednisone dose. All patients with suspected or biopsy-proven ACR episodes (grade $\geq 2 \mathrm{R}$ ) were treated with $3 \mathrm{~g}$ methylprednisolone i.v. over 3 days. In cases of hemodynamic compromise or severe rejection (grade $\geq 3 \mathrm{R}$ ), rabbit anti-thymocyte globulin was givenfor 7-10 days.

\section{Rejection Monitoring and Post-Transplant Outcome Analysis}

Following transplantation, patients underwent surveillance endomyocardial biopsies once weekly for 4 weeks, biweekly for an additional 8 weeks, monthly until 6 months after transplantation, and bimonthly until 12 months after transplantation. Thereafter, patients underwent endomyocardial biopsy at the discretion of their physician. Emergency endomyocardial biopsies were performed when warranted by the patient's clinical condition. The severity of ACR was determined using the ISHLT grading system. ${ }^{11}$ When antibody-mediated rejection (AMR) was suspected, patients were assessed for the presence of anti-human leukocyte antigen antibodies and endomyocardial specimens were subjected to immunofluorescence staining to determine the presence of pericapillary C4d positivity.

Patient survival was assessed from the time of transplantation until the end of the study period. The occurrence of ACR 


\begin{tabular}{|c|c|c|c|c|}
\hline & $\begin{array}{l}\text { No induction therapy } \\
\qquad(n=70)\end{array}$ & $\begin{array}{l}\text { Daclizumab induction } \\
(\mathrm{n}=98)\end{array}$ & $\begin{array}{l}\text { Basiliximab induction } \\
\qquad(n=67)\end{array}$ & P-value \\
\hline Age (years) & $54.9 \pm 14.1$ & $50.3 \pm 14.7$ & $55.8 \pm 11.2$ & 0.020 \\
\hline Male & $58(82.9)$ & $70(71.4)$ & $53(79.1)$ & 0.174 \\
\hline $\mathrm{BMI}\left(\mathrm{kg} / \mathrm{m}^{2}\right)$ & $26.6 \pm 6.4$ & $25.7 \pm 5.2$ & $25.8 \pm 4.7$ & 0.602 \\
\hline Etiology of heart failure & & & & 0.282 \\
\hline $\mathrm{ICM}$ & $33(47.1)$ & $33(33.7)$ & $23(34.3)$ & \\
\hline NIDCM & $30(42.9)$ & $48(49.0)$ & $37(55.2)$ & \\
\hline Congenital & $2(2.9)$ & $4(4.1)$ & $2(3.0)$ & \\
\hline Amyloidosis & $1(1.4)$ & $1(1.0)$ & $3(4.5)$ & \\
\hline Other & $4(5.7)$ & $10(10.2)$ & $2(3.0)$ & \\
\hline Diabetes & $17(24.3)$ & $21(21.4)$ & $15(22.4)$ & 0.564 \\
\hline Stroke & $5(7.1)$ & $6(6.1)$ & $10(14.9)$ & 0.142 \\
\hline PVD & $1(1.4)$ & $1(1.0)$ & $1(1.5)$ & 0.575 \\
\hline COPD & $2(2.9)$ & $3(3.1)$ & $4(6.0)$ & 0.412 \\
\hline VAD & $46(65.7)$ & $38(38.8)$ & $34(50.7)$ & 0.003 \\
\hline \multicolumn{5}{|l|}{ CMV status } \\
\hline $\mathrm{D}+/ \mathrm{R}_{-}$ & $14(20.3)$ & $21(21.6)$ & $13(19.4)$ & 0.204 \\
\hline $\mathrm{D}+/ \mathrm{R}+$ or $\mathrm{D}-/ \mathrm{R}+$ & $41(59.4)$ & $60(61.9)$ & $41(61.2)$ & 0.788 \\
\hline D-/R- & $14(20.3)$ & $16(16.5)$ & $13(19.4)$ & 0.845 \\
\hline Sodium (mEq/L) & $136 \pm 4$ & $136 \pm 4$ & $136 \pm 4$ & 0.277 \\
\hline Potassium (mEq/L) & $4.2 \pm 0.4$ & $4.2 \pm 0.7$ & $4.1 \pm 0.6$ & 0.231 \\
\hline Creatinine (mg/dl) & $1.4 \pm 0.6$ & $1.3 \pm 0.9$ & $1.4 \pm 0.5$ & 0.827 \\
\hline Total bilirubin (mg/dl) & $1.1 \pm 1.5$ & $1.6 \pm 3.6$ & $0.9 \pm 0.5$ & 0.172 \\
\hline Hemoglobin (mg/dl) & $10.9 \pm 2.0$ & $11.3 \pm 2.5$ & $11.8 \pm 2.5$ & 0.091 \\
\hline Hematocrit (\%) & $33.8 \pm 6.6$ & $34.6 \pm 7.0$ & $36.2 \pm 6.1$ & 0.094 \\
\hline WBC $\left(\times 10^{3} / \mu \mathrm{l}\right)$ & $7.6 \pm 2.3$ & $7.7 \pm 3.0$ & $7.4 \pm 2.7$ & 0.846 \\
\hline Platelets $\left(\times 10^{3} / \mu \mathrm{l}\right)$ & $210 \pm 82$ & $222 \pm 77$ & $198 \pm 72$ & 0.159 \\
\hline
\end{tabular}

Data given as mean \pm SD or $\mathrm{n}(\%)$. BMI, body mass index; CMV, cytomegalovirus; COPD, chronic obstructive pulmonary disease; D, donor; ICM, ischemic cardiomyopathy; NIDCM, non-ischemic dilated cardiomyopathy; PVD, peripheral vascular disease; $R$, recipient; VAD, ventricular assist device; WBC, white blood cell count.

\begin{tabular}{|lc|}
\hline Table 2. Reason for Not Receiving Induction Therapy \\
Active or recent history of infection & $46(65.7)$ \\
Retransplantation & $5(7.1)$ \\
Primary graft failure & $8(11.4)$ \\
Other & $11(15.7)$ \\
Total & $70(100)$ \\
\hline
\end{tabular}

Data given as $\mathrm{n}(\%)$.

(Grade $\geq 2 \mathrm{R}$ ) episodes as well as AMR within 1 year after transplantation was also analyzed. In the present study, AMR was defined as the presence of $\mathrm{C} 4 \mathrm{~d}$ on endomyocardial biopsy, regardless of the presence of allograft dysfunction.

\section{Statistical Analysis}

Continuous data are presented as mean \pm SD. Normality was evaluated for each variable from normal distribution plots and histograms. For data showing a bimodal distribution, such as non-Gaussian distribution or positive/negative skewness, logarithmic transformation of the variables was performed as needed to improve normality before performing statistical analyses. Variables were compared between the groups with Student's unpaired 2-tailed t-test. Analysis of variance, with Scheffé's F adjustment for multiple comparisons, was used to assess differences among groups. Categorical variables were compared using the Chi-squared test. $\mathrm{P}<0.05$ was considered significant. Post-transplant survival of patients was compared using Kaplan-Meier methods with the log-rank test. All data were analyzed using JMP 7.0 (SAS Institute, Cary, NC, USA).

\section{Results}

\section{Patient Characteristics}

In all, 235 adult patients were included in the analysis: 70 patients did not receive induction therapy, 98 patients received daclizumab induction therapy, and 67 received basiliximab. Patients receiving daclizumab were found to be younger (50.3 \pm 14.7 years) than patients receiving either no induction therapy (54.9 \pm 14.1 years) or basiliximab induction therapy $(55.8 \pm 11.2$ years; $\mathrm{P}=0.02)$. There were no significant differences in any other baseline demographics among the groups (Table 1).

One hundred and eighteen patients $(50.2 \%)$ required VAD therapy prior to HTx, whereas $117(49.8 \%)$ did not. Of those patients with a history of VAD therapy, $72(61 \%)$ received IL-2 receptor antagonist induction therapy, whereas 93 of 117 patients $(79.5 \%)$ without a history of VAD therapy were treated with induction therapy $(\mathrm{P}=0.001)$. Patients who required a VAD and received no induction $(n=46)$ did so for the following reasons: 35 patients $(76.1 \%)$ had an active or recent history of infection; $4(8.7 \%)$ experienced primary graft failure; and $2(4.4 \%)$ underwent retransplantation. The site of VAD- 


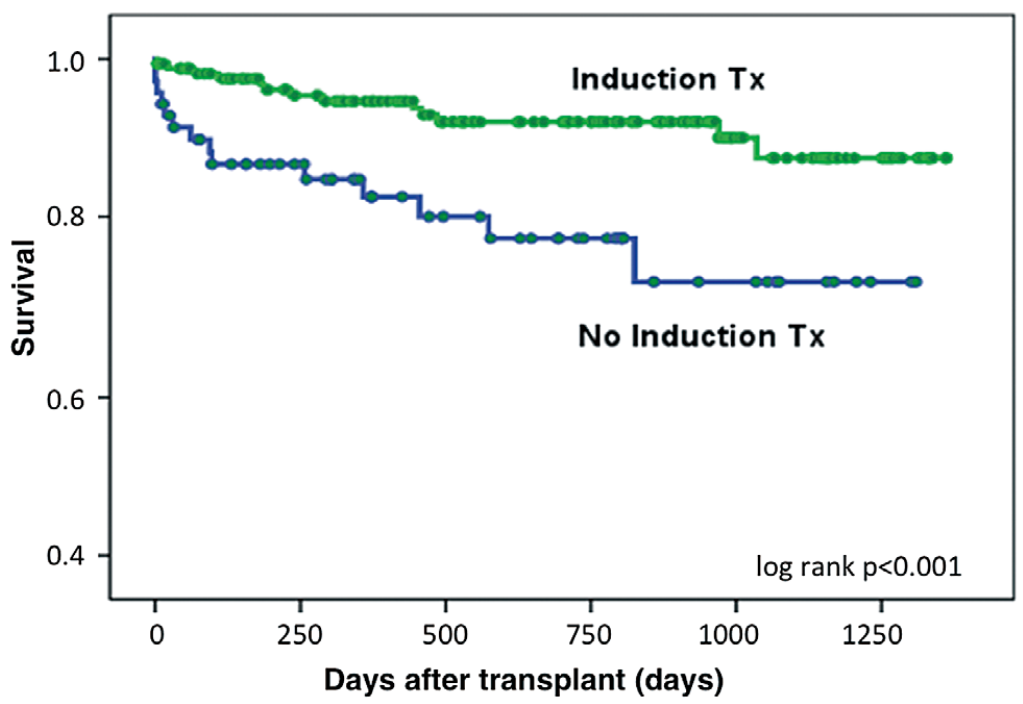

Figure 1. Overall survival after heart transplant for patients receiving any interleukin (IL)-2 receptor antagonist as induction therapy (Tx) compared with patients not receiving induction therapy. Blue, no induction Tx; green, either daclizumab or basiliximab induction $T x$.

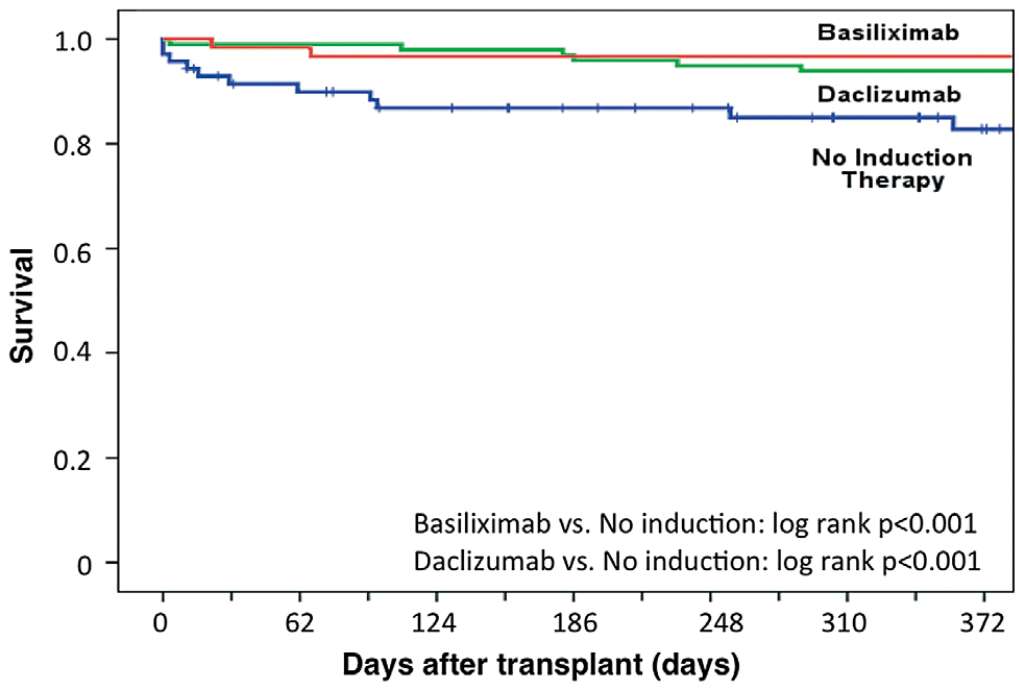

Figure 2. Survival up to 1 year for patients receiving daclizumab vs. basiliximab vs. no induction therapy. Blue, no induction therapy; green, daclizumab induction therapy; orange, basiliximab induction therapy.

related infection in these 35 patients without induction therapy was driveline infection in $16(45.7 \%)$, pocket infection in 11 $(31.4 \%)$, sepsis in $5(14.3 \%)$ and combined sternal woundrespiratory infections in $3(8.6 \%)$. Of the patients without a history of VAD placement who did not receive induction therapy $(\mathrm{n}=24), 11(45.8 \%)$ had infection, $4(16.7 \%)$ had primary graft failure, and $3(12.5 \%)$ underwent retransplantation. An overview of reasons for not receiving induction therapy is given in Table 2.

Of the patients who received either induction therapy, 107 $(65.8 \%)$ received tacrolimus as maintenance calcineurin inhibitor therapy. Of note, tacrolimus was used in $74.6 \%$ of patients who were given basiliximab, whereas tacrolimus was used in only $58.2 \%$ of those patients who received daclizumab. This discrepancy may be related to the gradual shift in immunosuppressant preference from a cyclosporin-based reg- imen to a tacrolimus-based regimen in recent years (daclizumab production ceased in 2009). Of those patients who did not receive any IL-2 receptor antagonists during the study period, $40 \%$ were maintained on tacrolimus. All other patients received cyclosporin as calcineurin inhibitor therapy.

\section{Survival}

At 1 year after transplantation, patients receiving IL-2 receptor antagonist induction therapy, either daclizumab or basiliximab, had significantly better survival $(95 \%)$ than those without induction therapy $(82 \% ; \mathrm{P}<0.001$; Figure 1$)$. When comparing basiliximab and daclizumab induction therapy, survival between patients was similar, but both induction therapy groups exhibited significantly improved survival compared with patients who did not receive induction therapy $(\mathrm{P}<0.001$; Figure 2). Considering that an active or recent history of in- 


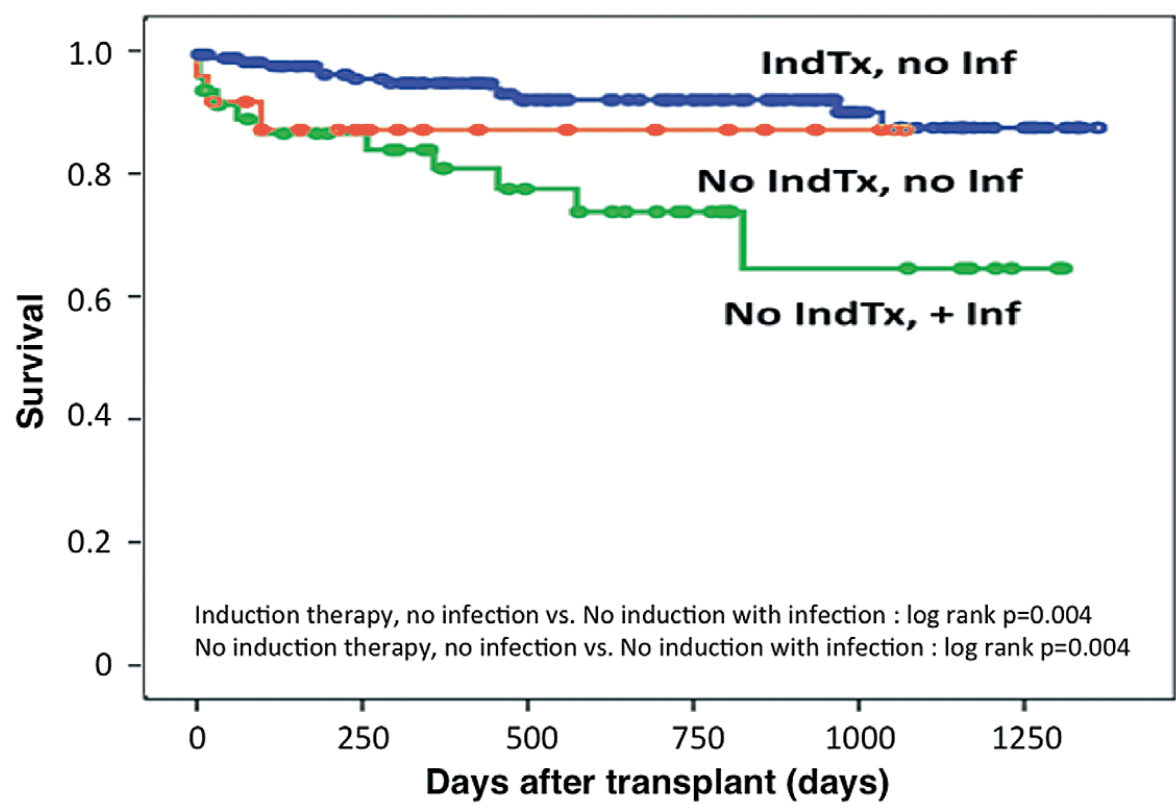

Figure 3. Survival of patients who did not receive induction therapy (IndTx) due to infection (Inf) compared with patients who did not have known infectious complications. Blue, IndTx and no Inf; orange, no IndTx and no Inf; green, no IndTx and Inf.

fection was the most common reason for withholding induction therapy, an analysis was performed to determine the potential confounding effects on survival (Figure 3). Patients not receiving induction therapy and having no history of infection $(\mathrm{n}=24)$ had similar survival to patients receiving induction therapy $(n=165)$. Patients who did not receive induction therapy due to infection $(n=46)$ were found to have worse overall survival $(\mathrm{P}=0.004)$.

\section{Rejection}

Within 1 year of transplantation, $12(17.1 \%)$ of the patients not receiving any induction therapy experienced an episode of ACR grade $\geq 2 \mathrm{R}$. This was not considered significantly different compared with the $8(8.2 \%)$ and $9(13.4 \%)$ patients who developed episodes of ACR grade $\geq 2 \mathrm{R}$ in the daclizumab and basiliximab groups, respectively. AMR occurred in $8(11.4 \%)$ patients who did not receive induction therapy, in $13(13.3 \%)$ patients receiving daclizumab induction therapy, and in $5(7.5 \%)$ patients receiving basiliximab induction therapy; the differences among the groups did not reach statistical significance. The proportion of patients who experienced recurrent ACR and/or AMR, defined as more than 3 episodes of rejections, tended to be higher in the group not receiving any induction therapy than in patient groups receiving either induction therapy $(7 / 70,10 \%$ vs. $7 / 165,4.2 \% ; \mathrm{P}=0.0881)$.

\section{Discussion}

The goal of the present analysis was to determine differences in clinical outcomes of heart transplant recipients receiving basiliximab or daclizumab as induction therapy. Our data suggest that: (1) survival in patients receiving either induction therapy was better than that of patients without induction therapy; (2) the survival of patients who received basiliximab as induction therapy was equivalent to that of patients who received daclizumab; (3) the most common reason for withholding induction therapy at our center was ongoing or recent infection prior to transplantation, which may be related to the poor prognosis of patients without induction therapy.

Literature evaluating the efficacy and safety of IL-2 receptor antagonists in heart transplant patients is robust but, to our knowledge, the present is the first comparison of daclizumab and basiliximab as induction therapy in heart transplant recipients. In particular, daclizumab has been established as an effective induction therapy in several randomized trials for both heart and kidney transplantation.9,10,12 Unfortunately, the drug is not available right now. Therefore, the current alternative to daclizumab, namely basiliximab, has to be proven to be equally effective when used as induction therapy. However, studies reporting such comparisons have not yet been performed in the field of HTx, only for renal transplants. In this regard, we believe that the findings of the present analysis may provide clinically important information.

Columbia University Medical Center previously published a small prospective investigation that compared transplant recipients receiving daclizumab induction therapy $(n=28)$ with a control group without induction therapy $(n=27) .{ }^{9}$ In that study, induction therapy with the IL-2 receptor blocker daclizumab significantly reduced the frequency and severity of ACR. ${ }^{9}$ However, because that study considered any symptoms of heart failure or evidence of hemodynamic compromise to be rejection, regardless of whether patients were found to have evidence of rejection on histology (grade $\geq 2$ ), it is difficult to make a true comparison of efficacy. Hershberger et al performed the largest randomized prospective trial of IL-2 receptor antagonist induction in heart transplant recipients. ${ }^{10}$ When comparing a dose of $1 \mathrm{mg} / \mathrm{kg}$ daclizumab $(\mathrm{n}=216)$ on POD 0 , $8,22,36$ and 50 with placebo $(n=218)$, the authors found that 
the primary composite endpoint (ACR, death, hemodynamic compromise, and retransplantation) at 6 months was significantly higher in the placebo group $(47.7 \%$ vs. $35.6 \%$; $\mathrm{P}=0.007) .{ }^{10}$ Although underpowered, a randomized, prospective trial comparing basiliximab $(n=25)$ with placebo $(n=31)$ in heart transplant recipients found no significant difference between the 2 groups with regard to the incidence of ACR, hemodynamic compromise, retransplantation, or death. ${ }^{13} \mathrm{Un}$ fortunately, we were not able to obtain the cause of death from all patients who died after transplantation in the present cohort because some of the deaths occurred at home or in local hospitals. However, although we failed to demonstrate the superiority of using induction therapy in preventing ACR and/or AMR, the number of patients developing recurrent rejection episodes tended to be smaller with either induction therapy compared with no induction. We speculate that preventing recurrent rejection during the early postoperative phase by using induction therapy has a beneficial effect on the postoperative prognosis in this patient type.

In an attempt to examine whether induction therapy with daclizumab is safe compared with placebo, a retrospective chart review of 3,209 cardiac transplant recipients (daclizumab, $\mathrm{n}=684$; control, $\mathrm{n}=2,525$ ) from January 1998 to October 2003 was performed. ${ }^{14}$ The authors of that study determined that the use of daclizumab did not negatively affect patient survival or increase the risk of death as a result of infectious complications. Despite no impact on survival, patients were found to have less ACR in the daclizumab group at both $6(15.6 \%$ vs. $20.4 \% ; \mathrm{P}=0.005)$ and 12 months $(34.9 \%$ vs. $42.1 \% ; \mathrm{P}<0.001)$ after transplantation.

Studies investigating differences between daclizumab and basiliximab in transplant recipients were found only in the renal transplant field. In renal transplantation, a prospective trial comparing daclizumab $(n=13)$ with basiliximab $(n=10)$ found similar rates of ACR after 6 months and survival at 1 year. ${ }^{15}$ However, a similar comparison in another study (basiliximab, $\mathrm{n}=30$; daclizumab, $\mathrm{n}=28$ ) found that 7 patients who received daclizumab had ACR at 6 months compared with no patients in the basiliximab group. ${ }^{16}$ In addition, a large headto-head comparison of basiliximab $(n=107)$ and daclizumab $(n=105)$ was performed in a randomized prospective analysis of deceased donor renal transplant recipients. ${ }^{17}$ In that study, biopsy-confirmed ACR at 12 months was found in $11(10.3 \%)$ basiliximab recipients and in $10(9.5 \%)$ daclizumab patients. Patient survival 1 year after transplantation was $97.2 \%$ and $97.1 \%$ in the basiliximab and daclizumab groups, respectively. ${ }^{17}$ In the present study, we found similar rates of ACR in the basiliximab and daclizumab groups.

Our analysis highlights the impact of perioperative comorbidities on overall patient survival. Patients with a recent history of infection, specifically associated with VAD therapy, had a significantly higher risk of death during the follow-up period compared with those without infection, regardless of induction strategy. Patients undergoing HTx and not receiving therapy due to reasons other than infection had similar survival compared with patients who received induction therapy (Figure 3). Admittedly, there was no difference in survival between the induction and no induction groups when patients had no infection. However, induction therapy may prevent early postoperative deaths even in patients without infection, as shown in the present study, which could contribute to better long-term outcomes. In addition, we speculate that the reason why perioperative infection impacted on late survival was because we need to minimize early postoperative immunosuppressive regimens, including no use of induction therapy in patients with infection, which sometimes causes not severe but subclinical rejection during the early postoperative period. A previous study found that even a low-grade rejection can lead to more severe and recurrent episodes of rejection if not treated early. ${ }^{18}$ We could not demonstrate a relationship between antibiotic therapy and renal dysfunction in patients with infection. Further investigations are needed to elucidate the impact of perioperative infection and its effects on long-term outcome. Indeed, all recipients received prophylactic antibiotics regardless of the presence or absence of infection at the time of transplantation. Renal function did not differ significantly between patients with and without infection. As noted here, further studies are needed to determine the long-term effects of perioperative infection.

Aside from an increased risk of infection with both basiliximab and daclizumab, as well as hyperglycemia associated with the use of daclizumab, the IL-2 receptor antagonists produce similar side-effect profiles to placebo. A distinct advantage of basiliximab induction therapy is its simplified dosing schedule of $20 \mathrm{mg}$ on POD 0 and 4, compared with daclizumab $1 \mathrm{mg} / \mathrm{kg}$ on POD $0,14,28,42$, and 56 . This smaller number of infusions required, and the reduced length of therapy, may significantly alleviate the potential burden on healthcare resources in outpatient infusion clinics.

The authors acknowledge that this analysis contains several limitations. Columbia University Medical Center's practice of avoiding induction therapy in patients with an active or recent history of infection may have reflected an overall poor state of health, which, in turn, affected survival. In addition, there were variations in the use of tacrolimus or cyclosporin for calcineurin inhibitor therapy. However, the choice of calcineurin inhibitor therapy was not based on efficacy, but rather the potential for unwanted complications based on individual patient risks and physician preference. The increased use of tacrolimus in the basiliximab group can be attributed to increased familiarity with tacrolimus use since basiliximab became the induction therapy of choice in 2010. Due to the retrospective nature of this analysis, patients were not randomized. Complications associated with potent immunosuppression, such as malignancy, were not assessed. We did not include pediatric recipients in the present analysis, although the frequency of use of any induction therapy in pediatric patients, including IL-2 inhibitors, has been increasing recently. ${ }^{19}$ The number of pediatric transplants is expected to increase in Japan and other Asian countries, ${ }^{20,21}$ therefore, verification of the safety and efficacy of this drug in pediatric patients would be particularly warranted. Further, we were unable to analyze the association between induction therapy and the occurrence of transplant coronary artery disease because we did not perform coronary angiograms on the present patients. A prospective randomized trial is required to appropriately determine the significance of our findings and distinguish which patients derive the most benefit from IL-2 inhibition as induction therapy.

Survival following HTx is comparable regardless of the IL-2 receptor antagonist used, and basiliximab is a suitable replacement therapy for those institutions that previously used daclizumab. On the basis of the present comparison of daclizumab and basiliximab, the withdrawal of daclizumab from the market is not likely to have a detrimental outcome on patients receiving IL-2 receptor antagonists as induction therapy. The use of induction therapy provides a survival benefit; however, due to the concerns regarding worsening infection, induction therapy was less frequently used in patients with ongoing active infection at the time of transplant, especially in 
patients supported by a VAD. Careful attention to prevent infection, especially in patients on a VAD, may expand the use of induction therapy at the time of transplant, which may further improve late survival in heart transplant recipients.

\section{Disclosures}

Dr Schulze was supported by grants from the National Institutes of Health (NIH; K23HL095742-01, P30HL101272-01) and the Irving Institute of Clinical and Translational Research of Columbia University. Dr Kato was supported by the National Center for Advancing Translational Sciences, through the NIH (UL1 TR000040). All other authors have no disclosures to report.

\section{References}

1. Stehlik J, Edwards LB, Kucheryavaya AY, Benden C, Christie JD, Dobbels F, et al. The registry of the International Society of Heart and Lung Transplantation: Twenty-eighth adult heart transplant report - 2011. J Heart Lung Transplant 2011; 30: 1078-1094.

2. Toyoda Y, Guy TS, Kashem A. Present status and future perspectives of heart transplantation. Circ J 2013; 77: 1097-1110.

3. Lindenfeld J, Miller GG, Shakar SF, Zolty R, Lowes BD, Wolfel EE, et al. Drug therapy in heart transplant recipient: Part I: Cardiac rejection and immunosuppressive drugs. Circulation 2004; 110: $3734-$ 3740 .

4. Baran DA, Zucker MJ, Arroyo LH, Camacho M, Goldschmidt ME, Nicholls SJ, et al. A prospective, randomized, trial of single-drug versus dual-drug immunosuppression in heart transplantation. Circ Heart Fail 2011; 4: 129-137.

5. Ensor CR, Cahoon WD Jr, Hess ML, Kasirajan V, Cooke RH. Induction immunosuppression for orthotopic heart transplantation: A review. Prog Transplant 2009; 19: 333-342.

6. Costanzo MR, Dipchand A, Starling R, Anderson A, Chan M, Desai $\mathrm{S}$, et al; International Society of Heart and Lung Transplantation Guidelines. The International Society of Heart and Lung Transplantation guidelines for the care of heart transplant recipients. J Heart Lung Transplant 2010; 29: 914-956.

7. Gabardi S, Martin ST, Roberts KL, Grafals M. Induction immunosuppressive therapies in renal transplantation. Am J Health Syst Pharm 2011; 68: 211-218.

8. Halloran PF. Immunosuppressive drugs for kidney transplantation. N Engl J Med 2004; 351: 2715-2729.

9. Beniaminovitz A, Itescu S, Lietz K, Donovan M, Burke EM, Groff $\mathrm{BD}$, et al. Prevention of rejection in cardiac transplantation by blockade of the interleukin-2 receptor with monoclonal antibody. $N$ Engl J Med 2000; 342: 613-619.
10. Hershberger RE, Starling RC, Eisen HJ, Bergh CH, Kormos RL, Love RB, et al. Daclizumab to prevent rejection after cardiac transplantation. N Engl J Med 2005; 352: 2705-2713.

11. Stewart S, Winters GL, Fishbein MC, Tazelaar HD, Kobashigawa J, Abrams J, et al. Revision of the 1990 working formulation for the standardization of nomenclature in diagnosis of heart rejection. $J$ Heart Lung Transplant 2005; 24: 1710-1720.

12. Vincenti F, Kirkman R, Light S, Bumgardner G, Pescovitz M, Halloran $\mathrm{P}$, et al. Interleukin-2-receptor blockade with daclizumab to prevent acute rejection in renal transplantation. $N$ Engl J Med 1998; 338: $161-165$.

13. Mehra MR, Zucker MJ, Wagoner L, Michler R, Boehmer J, Kovarik $\mathrm{J}$, et al. A multicenter, prospective, randomized, double-blind trial of basiliximab in heart transplantation. J Heart Lung Transplant 2005; 24: $1297-1304$

14. Kobashigawa J, David K, Morris J, Chu AH, Steffen BJ, Gotz VP, et al. Dalcizumab is associated with decreased rejection and no increased mortality in cardiac transplant patients receiving MMF, cyclosporine, and corticosteroids. Transplant Proc 2005; 37: $1333-$ 1339.

15. Nair MP, Nampoory MR, Johny KV, Costandi JN, Abdulhalim M, El-Reshaid W, et al. Induction immunosuppression with interleukin-2 receptor antibodies (basiliximab and daclizumab) in renal transplant recipients. Transplant Proc 2011; 33: 2767-2769.

16. Lin M, Ming A, Zhao M. Two-dose basiliximab compared with twodose daclizumab in renal transplantation: A clinical study. Clin Transplant 2006; 20: 325-329.

17. Kandus A, Arnol M, Omahen K, Oblak M, Vidan-Jeras B, Kmetec A, et al. Basiliximab versus daclizumab combined with triple immunosuppression in deceased donor renal transplantation: A prospective, randomized study. Transplantation 2010; 89: 1022-1027.

18. Kato TS, Oda N, Hashimura K, Hashimoto S, Nakatani T, Ueda HI, et al. Strain rate imaging would predict sub-clinical acute rejection in heart transplant recipients. Eur J Cardiothorac Surg 2010; 37: $1104-1110$.

19. Dipchand AI, Kirk R, Edwards LB, Kucheryavaya AY, Benden C, Christie JD, et al. The Registry of the International Society for Heart and Lung Transplantation: Sixteenth Official Pediatric Heart Transplantation Report - 2013; focus theme: Age. J Heart Lung Transplant 2013; 32: 979-988.

20. Cha MJ, Lee HY, Cho HJ, Hwang HY, Kim KB, Oh BH. Underutilization of donor hearts in the initial era of the heart transplant program in Korea: Review of 13 years' experience from the Korea National Registry. Circ J 2013; 77: 2056-2063.

21. Ueno T, Fukushima N, Sakaguchi T, Ide H, Ozawa H, Saito S, et al. First pediatric heart transplantation from a pediatric donor heart in Japan. Circ J 2012; 76: 752-754. 